\title{
Anomaly Detection System Using Digital Image Processing for The Indian Railways
}

\author{
Sharmista Shastry ${ }^{1}$, Amartya Anshuman ${ }^{1}$, Vedant Tibrewal ${ }^{1}$, Yogesh Kumar Choukiker ${ }^{2}$ \\ ${ }^{1}$ B. Tech, Electronics and Communication, Vellore Institute of Technology, Vellore, Tamil Nadu, India \\ ${ }^{2}$ Associate Professor, Vellore Institute of Technology, Vellore, Tamil Nadu, India
}

\begin{abstract}
Article Info

Volume 8, Issue 4

Page Number : 186-190

\section{Publication Issue}

July-August-2021

\section{Article History}

Accepted : 02 July 2021

Published : 10 July 2021

The Indian Railways are the lifeline of India's transport system. Being the fourth largest railway network in the world, it covers the length and breadth of the country. In 2018-19, 23.12 million people and 3.36 million metric tons of freight depended on the railways on a daily basis. They bind the economic life of the country and foster the development of industry and agriculture. However, poor maintenance of the railway tracks has caused several accidents over the years. Derailments due to the presence of faults in railway tracks cause heavy loss of life and railway property. Therefore, timely detection and analysis of these cracks is of utmost importance. This proposal aims at providing a cost effective solution to the problem of fault detection in railway tracks using digital image processing.

Keywords : Railway Track, Fault Detection, Digital Image Processing.
\end{abstract}

\section{INTRODUCTION}

The Indian Railways have always been a crucial factor in influencing the trade and market. They allow the production and consumption of products at various locations. India's economy has always been contingent upon proper function of the railways. Being the cheapest mode of transport, they attract a huge volume of traffic every day. They remove isolation between cities and provide a strong medium for national integration. However, several mishaps occur from time to time due to negligence in maintenance and inaccurate monitoring of railway tracks for faults. A real time anomaly detection system helps tackle the issues that arise with manual monitoring of the railway tracks. Digital image processing allows us to implement a cost effective method to detect the cracks present on the track surface with optimum precision, with as less human intervention as possible. A system captures images of the railway track and sends them to the server, i.e, to the computer of the rail employee, where they are processed for any anomalies. This methodology helps in eliminating accidents caused due to faults in the railway track and saves lives and important assets. 


\section{LITERATURE SURVEY}

Continuous monitoring of the railway tracks is done on foot on a daily basis. The prevailing method faces numerous challenges. The person concerned with the inspection of faults on the railway tracks, has to cover several kilometers on foot. This may cause him to overlook some of the minor cracks present on the track surface. Patrolling through abnormal weather conditions like heavy rain, extreme cold and insufficient light during the night is also not feasible. This section presents the results of previous researchers regarding this problem.

Mao et al. proposed a method to detect the surface defects on the rail by minimizing the maximum between class variance. However, there could be substantial improvement in this method. He et al. used the mean background subtraction algorithm to detect the faults on the railway line. But, the method that he proposed lacked robustness. Raghupati et al. proposed a technique that used ultrasonic waves to locate the railway track deformities. However, the drawback with this technique was that this method would solely focus on the core of the railway tracks and not on or near the surface, where most faults are likely to be present. Tang et al. used gray level projection to segment and obtain rail surface area. But the algorithm that he used didn't have suitable adaptability. Yuan et al. improved upon this and used a better algorithm, the Otsu algorithm. But this algorithm too, was flawed as its threshold selection was not universal.

Although the existing methods have continuously sought to improve accuracy in detecting the faults, there is much to be done still and at the same time, there is also a need to reduce the costs involved.

\section{SYSTEM DESCRIPTION}

\section{A. Working of Project}

The importance of timely data acquisition and analysis of railway track surfaces is extremely crucial. To achieve timeliness and accuracy in track inspection, automation of data acquisition and analysis is necessary.

The techniques involved in this project on automated crack-detection techniques for the track inspection process, are based on imaging edge-detection algorithms. This project proposes and demonstrates a framework for evaluating the effectiveness of imaging crack-detection algorithms in

inspecting surface of railway tracks. Edges in digital images are defined as sharp intensity transitions. Edge-detection algorithms seek to detect and localize edges without any input or interference from humans.

A sample of 5 track images were used in the analysis. The images were all gray-scale images with a resolution of $640 \times 480$ pixels. The images used did not include any background such as grass or motor vehicle traffic. Ideally, a stationary, bridge-mounted camera would focus directly onto the crack, but if background is included in the image, it may be necessary to include a prefilter to eliminate such anomalies.

A MATLAB code was developed for the algorithm to read the images, perform the transforms, and output the isolated cracks, usually referred to as the edge image. The edge image was recorded for for each of the 5 images. Based on the threshold value for the algorithm and the intensity in the edge image, an output image was determined to have a crack or no crack. A threshold value is a parameter that is crucial to the performance of any edge-detection algorithm. 
Based on the value of this parameter, it is decided if a crack exists or not.

\section{B. Block Diagram}

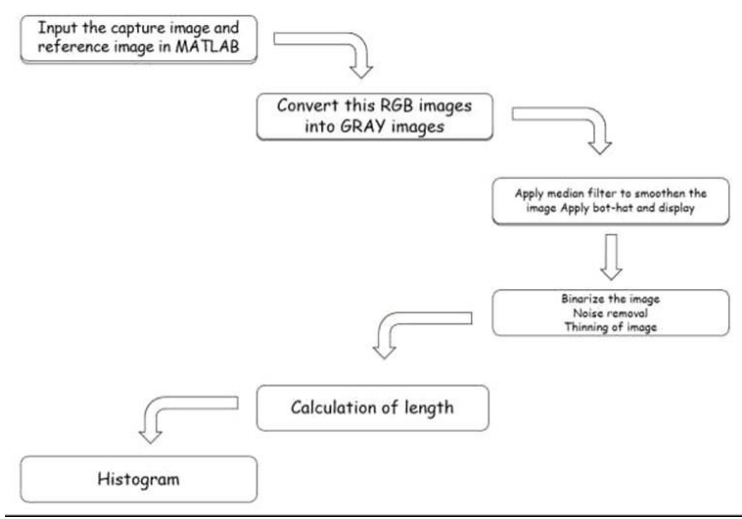

Fig 1. Block Diagram

\section{SIMULATION RESULTS}

The algorithm was implemented with the help of MATLAB 2013a software tool. The following are the results of the simulation.

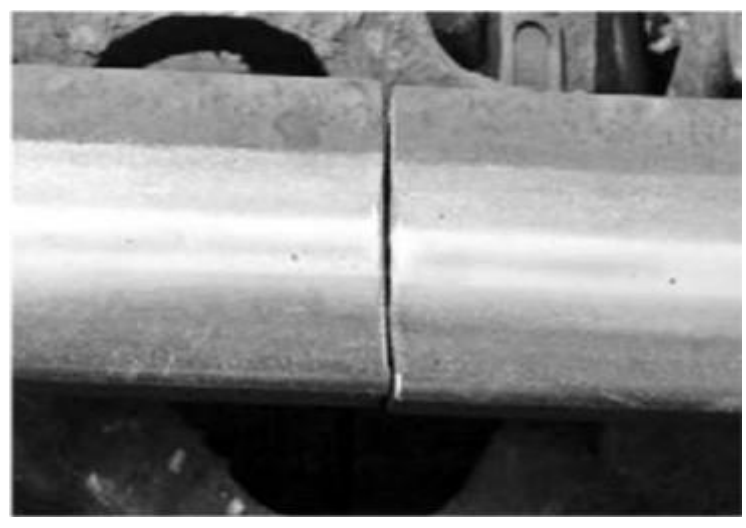

Fig 2a. Image after gray conversion

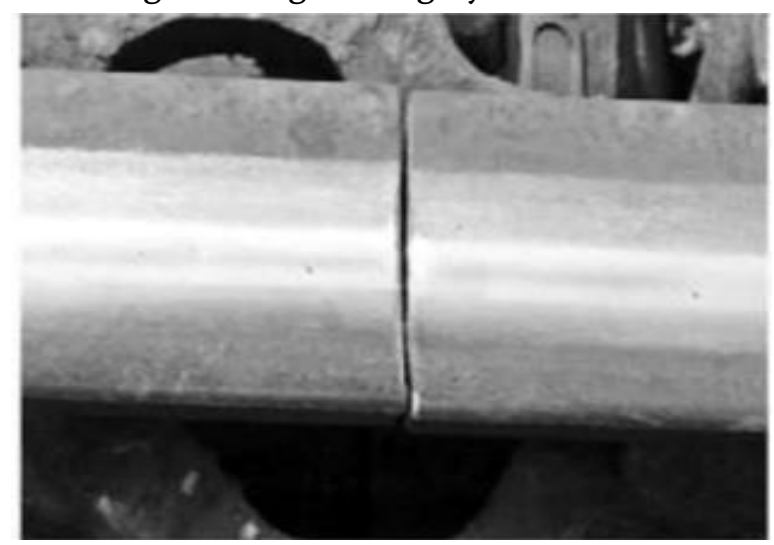

Fig 2b. Image after applying median filter
Fig 2a. shows the results after converting the image from rgb to gray-scale and Fig $2 b$. shows the results after applying the median filter to enhance the image.

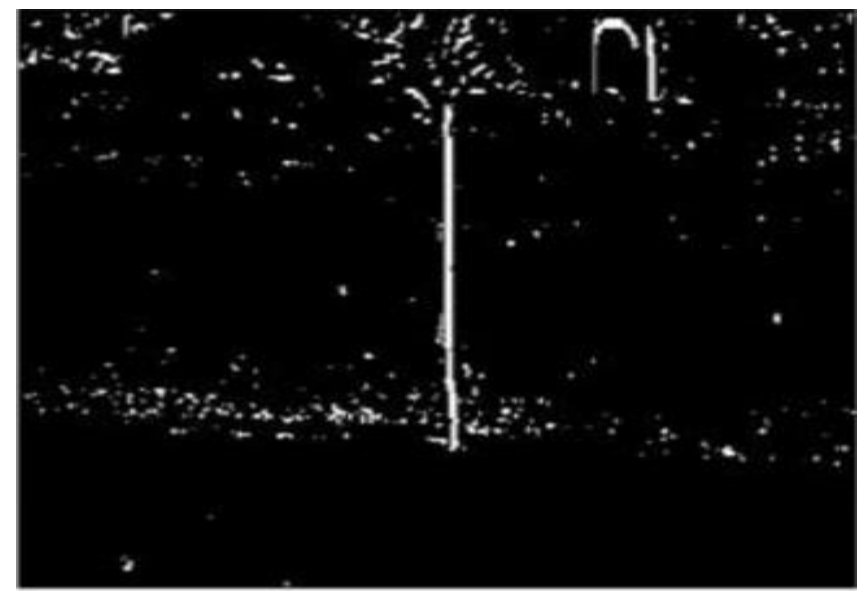

Fig 2c. Binary Image

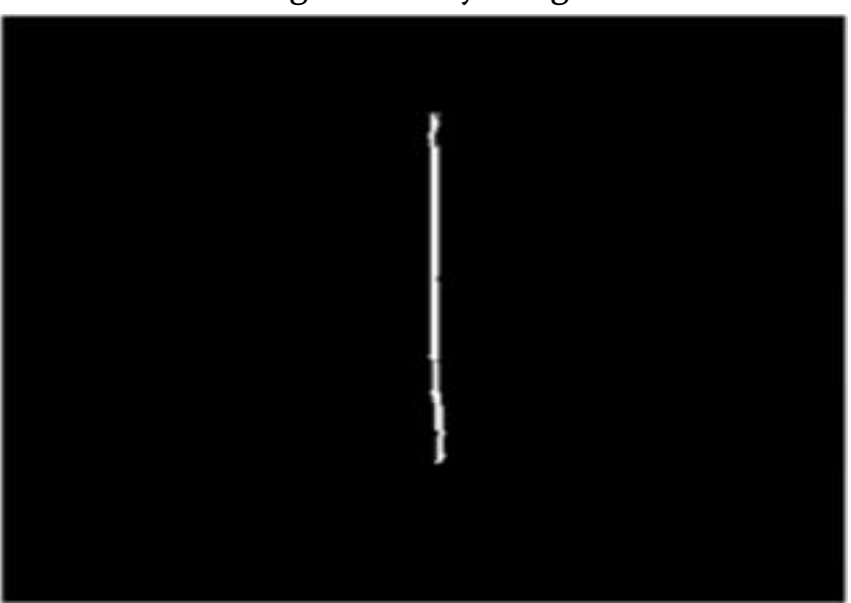

Fig 2d. Image after noise removal

The image is then converted into a binary image and the noise present in the image is also removed. This is illustrated in Fig 2c. and 2d.

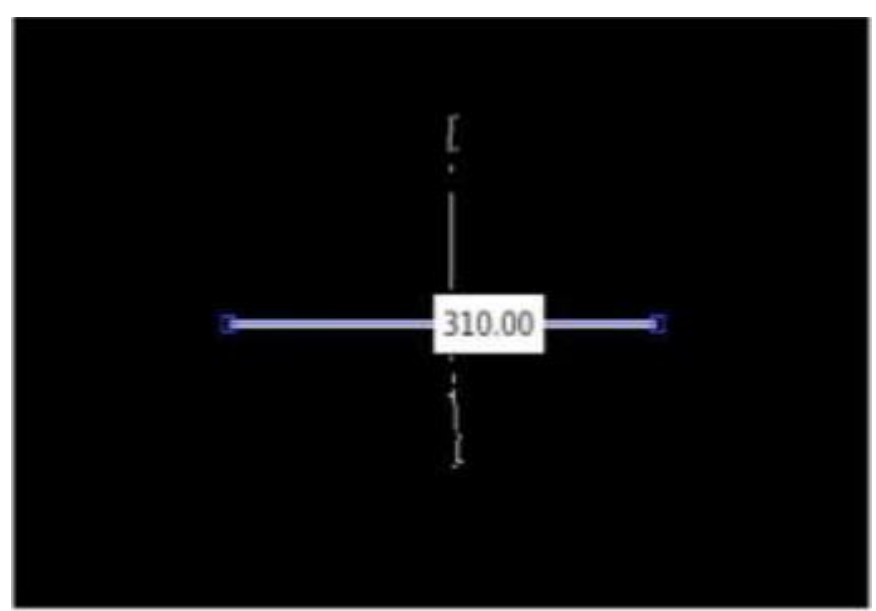

Fig 2e. Dimensions of the crack 


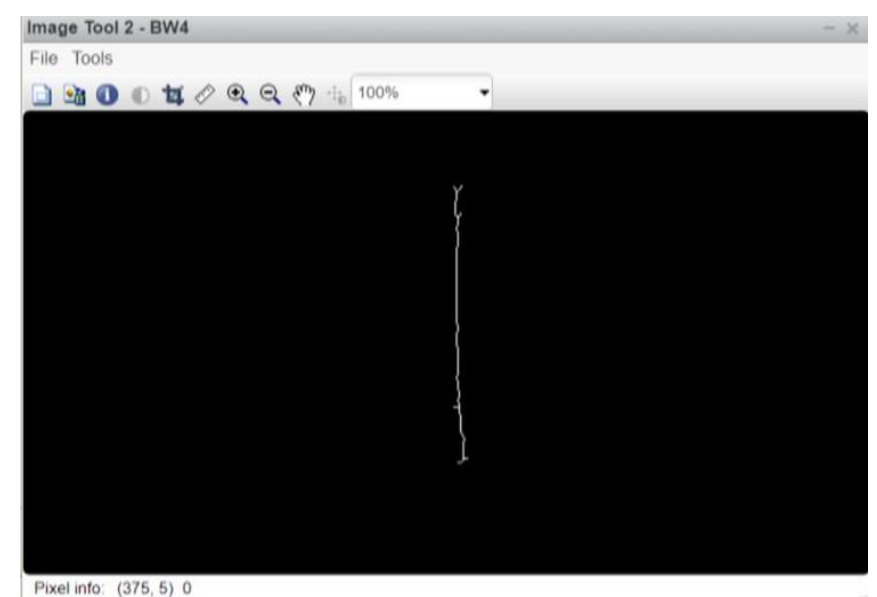

Fig 2f. Isolated railway track fault image

Fig 2e. And 2f. show the edge image obtained along with its dimensions in the simulation. The crack is detected based on a certain threshold level.

\section{CONCLUSION}

In this paper, a method has been proposed to detect the faults present on the railway track surface, using digital image processing. Pictures of the track are taken with a drone and given as input to the suggested system to detect cracks. This will help to detect cracks immediately and reduce the possibilities of accidents. As the system is automated, with minimum manual intervention, the system would be highly efficient.

\section{REFERENCES}

[1]. Tastimur, E. Akın, M. Karaköse, and İ. Aydın, “ Detection of rail faults using morphological feature extraction based image processing", 2015 23rd Signal

[2]. Processing and Communications Applications Conference (SIU), pp. 1244 - 1247, DOI: 10.1109/SIU.2015.7130063, 2015.

[3]. M. Molodova, Z. Li, A. Núñez and R. Dollevoet, "Monitoring the Railway Infrastructure:
Detection of Surface Defects Using Wavelets", Proceedings of the 16th

[4]. International IEEE Annual Conference on Intelligent Transportation Systems (ITSC 2013), The Hague, The Netherlands, October 6-9, 2013

[5]. Esther Resendiz, Me mber, IEEE, John M. Hart, and Narendra Ahuja, Fellow, IEEE " Automated Visual Inspection of Railroad Tracks" I EEE transaction on intelligent transportation systems, vol 14, no.2, June 2013

[6]. An Introduction to Digital Image Processing with Matlab, Notes for SCM2511 ImageProcessing 1, Semester 1, 2004, Alasdair McAndrew, School of Computer Science and Mathematics, Victoria University of Technology

[7]. Yuvashree G, S. Murugappriya," Railway Track Inspection System for Railbolt and Crack Fault Detection", IJEEE, Volume 07, Issue 01, JanJune 2015

[8]. S. Wender and K. Dietmayer, "3D vehicle detection using a laser scanner and a video camera," Intelligent Transport Systems, IET, vol. 2, pp. 105- 112, 2008. ।

[9]. https://www..mathworks..com

[10]. Z. Mao, Y. Zhan, G. Tao, B. Jiang, and X.G. Yan, "Sensor Fault Detection for Rail Vehicle Suspension Systems with Disturbances and Stochastic Noises", IEEE Transactions on Vehicular Technology, Vol. PP, Issue 99, pp. 11, do1: 10.1109/TVT.2016.2628054, 2016

[11]. Min Y, Xiao B, Dang J, Yue B, Cheng T. Real time detection system for rail surface defects based on machine vision. EURASIP Journal on Image and Video Processing. 2018 Dec 1;2018(1):3.

[12]. Tang XN, Wang YN. Visual inspection and classification algorithm of rail surface defect. Computer Engineering. 2013;39(3):25-30 


\section{Cite this article as :}

Sharmista Shastry, Amartya Anshuman, Vedant Tibrewal, Yogesh Kumar Choukiker, "Anomaly Detection System Using Digital Image Processing For The Indian Railways", International Journal of Scientific Research in Science and Technology (IJSRST), Online ISSN : 2395-602X, Print ISSN : 23956011, Volume 8 Issue 4, pp. 186-190, July-August 2021. Available at doi : https://doi.org/10.32628/IJSRST2183186 Journal URL : https://ijsrst.com/IJSRST2183186 